account of the following case we are indebted to Mr. W. H. Carthew Davey, senior house surgeon.

J. A-_, aged fifty-five, was admitted into the hospital on Nov. 14th, 1889, with symptoms of pyloric obstruction. The case presents such interest from a surgical point of view that the account of its medical aspect must be brief. The symptoms and physical signs were those usually met with in this disease, with one or two exceptions. 1st. The presence of a tumour under cover of the left costal cartilages, on a level with the umbilicus, thought to be a displacement of the pylorus (this was verified at the operation). 2 2nd. The length of time elapsing between the taking of food and the occurrence of vomiting, the longest time being thirty.six hours.

The treatment adopted for the first week was daily washring out of the stomach with a solution of borax and bicarbonate of soda; the diet consisted of pancreatised milk and beef-tea; but in spite of this treatment vomiting and loss of thesh continued, the patient losing $10 \frac{1}{2} \mathrm{lb}$. in weight in the week. Then came the question of surgical interference. Was it possible to remove the growth? If not, perhaps gastro-enterostomy would relieve the patient, for to allow him to remain in such a condition meant death at no distant date. It was then decided that an exploratory incision should be made. Accordingly Mr. Rawdon, assisted by Dr. Alexander, made an incision of about four inches in length extending from just below the ensiform cartilage to the umbilicus. After the peritoneum had been opened, the finger was introduced and the bearings of the tumour made out; it proved to be the pylorus and adjoining portion of the stomach. There were fortunately mo adhesions to neighbouring viscera; the diseased mass was therefore somewhat easily drawn up through the incision and surrounded by sponges; and it being found on examination that nearly one-third of the stomach was involved in the carcinomatous mass, it was decided to excise it. The vessels coursing along the curvatures of the stomach were ligatured at a point where the section of that viscus would have to be made. The duodenal mesentery was then torn through with the fingers, and a piece of small-sized rubber tubing passed round the bowel and tied in a knot; this was effectual in preventing any escape of its contents. The mass being well drawn out through the abdominal wound, and well packed round with warm antiseptic sponges, the affected parts were excised, two or three vessels in the coats of the stomach requiring a ligature. The duodenum was next cut through between the pylorus and the rubber tubing. The entire mass was now only attached by its omental connexions; these were gathered into a pedicle, transfixed, and tied. The severed duodenum was now well held forward and the rubber tubing taken off. Three or four arteries spurted, but were quickly tied. The incised edges of the stomach were stitched with a continuous suture of fine Chinese silk, after the method of Lembert. The suturing commenced at the lesser and proceeded towards the greater curvature, the suturing being discontinued one inch from the greater curvature, thus leaving an opening sufficiently large to admit the introduction of one of Senn's decalcified bone plates. A Senn's plate with four threads of Chinese silk attached was then inserted into the opening, and three out of the four of the silk threads attached were passed through the walls of the stomach, about one-sixth of an inch from its cut edges. A second plate was introduced into the duodenum, and the four silk threads attached to the plate were passed through the walls of the bowel a short distance from its cut margin. The plates were then brought into apposition and held firmly together while each corresponding pair of threads were securely tied, the lowest being tied first. Thus the serous surface of the bowel was brought into immediate contact with the serous surface of the stomach. The parts, after being carefully sponged, were replaced within the abdomen, the wound closed in the usual way, and antiseptic dressings applied. The patient rallied well after the operation. He was supported by nutrient enemata and suppositories. For the first six days, no food or drink being allowed by the mouth, he suffered intensely from thirst, which, however, he bore with great fortitude, and happily it became more and more endurable as time went on. One week -after the operation he was allowed a little pancreatised milk every hour; this was gradually increased, till about the twelfth day he was taking two pints of milk in the twenty. four bours. From now his convalescence was uninter. rupted, his diet being more liberal as time went on. At present his appetite and digestion are most satisfactory, he has no discomfort whatever after food, which he much relishes, and has gained nearly two stone in weight. $\mathrm{He}$ intends to resume work as a sailmaker very shortly.

\section{THE INFIRMARY, BURTON-ON-TRENT.}

A CASE OF COMPOUND COMMINUTED FRACTURE WITH WOUND OF BRAIN, FOLLOWED BY HERIIA CEREBRI ; RECOVERY.

\section{(Under the care of Mr. T. B. MAson.)}

HERNIA CEREBRI is a serious complication of any wound of the brain, and one which causes considerable anxiety as to the ultimate result. In the case of this patient it developed on the ninth day, and was apparently not cured until more than six weeks had elapsed, when it was noted as almost "level with the surrounding skin ;" during this time the patient emaciated, and suppuration took place around the protrusion. Professor Nancrede ${ }^{1}$ gives the average time for the development of hernia cerebri after wound of the brain as from the fifth to the seventeenth day, whilst it has appeared within the first twenty-four hours, and as late as the sixty-eighth day. Of eighty cases which be had collected from various sources, only twenty-five ended favourably. In all cases of cerebral wounds, the possibility of the development of this complication must be recollected, and the strictest antiseptic treatment employed; it is also of moment to remove causes of irritation and to secure primary union of the super-imposed wound of the soft parts. When the hernia has developed, there is a tendency at present ${ }^{2}$ to be satisfied with strict antiseptic cleanliness, and when it has become more chronic, with the employment of pressure. In some cases, however, as in this one, removal of the tumour has appeared to be of advantage, and there are several well-authenticated cases of recovery ; in others, removal has been followed by rapid recurrence and ultimately death from exhaustion or coma. Quesnay ${ }^{1}$ had a patient under his treatment who pulled off the protrusion himself and afterwards recovered. Maclaren ${ }^{3}$ put $a$ silver plate in the hole in the skull, leaving an interval for drainage, removing the hernia from time to time as it recurred. For the following notes we are indebted to the house surgeon, Mr. W. Gibson.

G. W. B—, aged six, was admitted on Sept. 19th, 1889, with a compound comminuted fracture of the skull, caused by a kick from a horse. The wound, which was much lacerated, was situated over the right frontal eminence, and a square inch of bone was driven into the brain. There was no paralysis, and the boy was able to give an account of the accident. Chloroform was administered, and Mr. Mason easily removed the piece of bone with dressing forceps. The wound was well irrigated with $l$ in 40 carbolic lotion, a drainage-tube inserted, and the edges brought together with three silver sutures, and dressed with protective and Gamgee tissue. The patient was ordered to take nothing but ice.

Sept. 20th. - Complains of headache ; no paralysis. Temperature $100^{\circ}$; pulse 125 , high tension. He was ordered three grains of calomel and seven grains of jalap. One pint of milk in the twenty.four hours was permitted to be taken.

21st. - The wound was dressed; there was no sign of healing.

28th. - The sutures have torn their way through the skin, and brain substance is seen to be fungating through the opening in the dura mater. There is no paralysis. A second piece of bone, nearly as large as the first, was found to be loose, so it was removed with a pair of dressing forceps.

30th. - Temperature $99^{\circ}$; pulse 100 . Hernia cerebri rapidly increasing in size; no paralysis, but pressure on the hernia causes flexion of the left elbow. The boy is rapidly emaciating.

Oct. 9th.-On more liberal diet the boy's condition has improved, but the hernia cerebri is about the size of a Tangerine orange.

10th. - Chloroform administered, and the hernia cerebri sliced off level with the skull. The hæmorrhage was free, but it was easily controlled by pressure with a pad of boric lint. No paralysis. 1 International Encyclopredia of Surgery, vol. v., p. 68.
2 Erichsen, vol. i., p. 784 . Holmes : Surgery, its Principles and Practice, p. 166. Walsham, p. 351 . Dictionary of Surgery: Brain (Hernia of). $\quad 3$ Clin. Soc. Trans., vol. xix., p. 159. 
11th. - Temperature : morning, $984^{\circ}$; evening, $104^{\circ}$.

12th. - As pus was burrowing under the orbicularis palpebrarum, a counter-opening was made, which gave relief, and the temperature fell to normal.

14 th. - The hernia is again rapidly increasing in size. Temperature normal.

20ch.-General condition much better. Boy sits up in bed and takes an interest in all that goes on in the ward. Temperature normal since the last note.

$22 \mathrm{nd}$. - Hernia larger than ever. Was again sliced off under chloroform without producing any symptoms, and dressed with iodoform and boric lint.

$28 \mathrm{th}$. - Dressed every day, as the discharge is abundant. Hernia again increasing, so firm bandaging was tried, with the result of causing slight but gradual diminution in size.

Nov, 12th. - Since the last note the hernia has been gradually diminishing, and it is now nearly level with the surrounding skin. The wound is granulating well, the boy has no paralytic symptoms, and lately he has been getting quite fat.

22nd. - As there is a hole in the skull about an inch and a half each way Mr. Mason has proposed to try the experiment of grafting some small strips of rabbit bone on to the granulating surface. This was done in the following manner: A young rabbit, about three weeks old, was killed and a piece of bone removed from its cranium and immediately inmersed in warm boracic lotion. Small strips were then cut off this and dropped on to the granulating surface. About a dozen were placed on altogether, some being the size of a pin's head, others about an eighth of an inch long.

24th. - On removing the dressing, which consisted of green protective and boric lint well strapped down, nosts of the pieces of bone came away, but three pieces were adberent.

28th. - The grafts have so stimulated the graulating surface that it is not above half its original size. One or two grafts are still adherent.

$30 \mathrm{th}$.- Another rabbit was killed, and the wound grafted. as before, excepting that a piece of periosteum from the cranium was also laid on this time.

Dec. 3rd.-The grafts have nearly all come away, and even the three old ones do not seem as though they would remain attached much longer.

20th. - Wound nearly healed, but the remaining grafts are quite dead.

Jan. 20th, 1890. - A shield has been supplied for the boy, which he was ordered to wear constantly, and he was discharged quite well.

Note by Mr. Mason.-Although the pieces of bone did not permanently become fixed, yet the transplantation seemed to start most rapid cicatrisation, the granulating surface not showing any sign of this before. Several pieces became distinctly vascular.

\section{interical Sorcietirs.}

\section{ROYAL MEDICAL \& CHIRURGICAL SOCIETY.}

Operation for Radical Cure of Non-strangulated Hernice.

AN ordinary meeting of this Society was held on April 8th, the President, Mr. Timothy Holmes, in the chair.

Mr. BARKER gave to the Society the results of a study of fifty consecutive cases of operation for the Radical Cure of Non-strangulated Herniæ. The series was studied with the following questions in view: 1 . Was the procedure called for? 2. Was it safe- $(\alpha)$ as regarded the patient's life; (b) as regarded the contents of the scrotum? 3. Did it secure against a return of the hernia? All the cases in the series were operated on for non-strangulated herniæ which were not amenable to other treatment. The first question was shown to be answered in the affirmative by common experience as far as selected cases went. The safety of the procedure was indicated by the absence of a single death or ill effect to the structures in the scrotum in any case among the fifty. True suppuration of the wound only occurred in two cases; the rest healed well. There were no cases of wound-infection or shock. In two instances the bowels were coughed out during the operation, but no ill effect followed. The stitches in the skin were usually removed on the tenth or twelfth day; those in the ring were left untonched. The ages of the patients varied from three months to seventy years. The numbers for each five years were given, as well as the varieties of rupture met with. Some of the details of operation were alluded to, and the general subsequent course of the cases during convalescence. The exanination of the question of security against recurrence was then undertaken, and the numbers were given of those which returned. Some conclusions which seemed to follow from the study of this series of cases were then given by the author.

Mr. BENNETT said that the procedure was called for, but less frequently than some night be Jed to believe. He would divide the cases into two classes: people who were still young and adults. In all young people, in whom there was a strong tendency to natural cure, there was very rarely need for operation; he observed, however, that the author's series contained a case of operation on an infant three months of age. He himself had never operated on any child under eighteen months, and he thought that the necessity for it earlier than this nust be extremely rare. In the adult there was no tendency in ordinary cases to a cure, and a large percentage of them required active treatment. The operation was safe as regarded the patient's life, provided it were done with ordinary care, though fatal cases had happened which had not been recorded. The question whether the contents of the scrotum would suffer depended on the manner in which they were treated. $\mathrm{He}$ had twice seen the testicle slough, and in each a serious attempt had been made to dissect away the sac from the scrotum. Yet the testis did not readily necrose, for in one instance he had seen the whole cord and vas deferens divided without harm happening to $i t$, and in operating for varicocele he commonly divided the spernatic artery without bad results; the structures of the cord, in fact, would bear a great amount of interference without danger. The question whether the operation secured the patient against a return of the rupture depended a great deal upon the age of the individual. Young patients were certainly cured ; but in the adult, in the vast majority of cases, the patient was relieved, but not cured, especially if the ring vere large and the sac contained much gut. The operation, however, did good, as it enabled the patient to wear truss with greater comfort. It was said by some that the pressure of a truss would lead to the absorption of the products thrown out in the attempt at cure. This was true if the truss were worn too soon, but not so if it were applied six months after the operation. He asked what was the effect in very young subjects of returning gut into the abdomen which had long been accustomed to be ontside; he believed it favoured the production of hernix in other situations. He had noticed the development of such secondary herniæ in at least three instances.

Mr. GREIG SMrTH said he would never operate on children, and rarely in irreducible hernia, unless the patient were in danger of life or incapacitated for work. The author's paper had shown that if the sac were divided at the neck it was unnecessary to remove the body and fundus from the scrotum, and that perfect closure of the external ring was an efficient means of completing a radical cure. He himself held strongly to the view that if the sac of the bernia were removed the patient was deprived of useful material for promoting a radical cure. If a truss had to be worn afterwards, he maintained that the cure was not a radical one. An operation to be thoroughly successful should produce a perfect cure with a very small risk to life, and of all methods hitherto published he thought Macewen's seemed to be the best. The aponeurosis of the external oblique in old hernix became almost semicircular at the ring, and was pulled down with difficulty. If a few longitudinal incisions were made, they would liberate the agglutinated fibres, and the ring could be effectually closed.

Mr. PARKER had operated on many cases in children in whom, in a large proportion of cases, the canal did not close up, and they would otherwise be saddled with a troublesome hernia which would be more dangerous if operated on later. His method was to expose the sac, sew up the neck, and then stitch the pillars of the ring; he cut away nothing, and did not divide the neck of the sac. He had lost no cases after the operation, though one had died of diphtheria after the wound had healed. He had not followed up his cases, hut he took it for granted that they were not at present suffering much from their ruptures.

Mr. PYE said that Mr. Bennett's explanation of the cause of secondary rupture was difficult to accept when the vary. ing condition of abdominal distension in infants was borne 